\title{
Delayed Vertebral Artery Dissection after Posterior Cervical Fusion with Traumatic Cervical Instability: A Case Report
}

\author{
Chang Hyun $\mathrm{Oh}^{1}$, Gyu Yeul $\mathrm{Ji}^{1,2}$, Seung Hwan Yoon ${ }^{3}$, Dongkeun Hyun ${ }^{3}$, Eun Young Kim ${ }^{3}$, \\ Hyeonseon Park ${ }^{3}$, A Reum Jang ${ }^{1}$ \\ ${ }^{I}$ Department of Neurosurgery, Guro Teun Teun Research Institute, Seoul, \\ ${ }^{2}$ Department of Neurosurgery, Yonsei University College of Medicine, Seoul, \\ ${ }^{3}$ Department of Neurosurgery, Inha University School of Medicine, Incheon, Korea
}

Vascular injury presented immediately after the penetration, but delayed onset of vascular symptom caused by an embolism or vessel dissection after cervical fusion or traumatic event is extremely rare. We present a case of a 56-year-old woman who underwent an operation for cervical fusion for type II Odontoid process fracture. She presented symptoms of seizure with hemiparesis in 6 days after the operation. Multifocal acute infarction due to an embolism from the left VA (V3 segment) dissection was observed without a definite screw breach the transverse foramen. We hereby reported the instructive case report of delayed onset of vertebral artery dissection after posterior cervical fusion with type II odontoid process fracture patient. When a cervical operation performed in the cervical trauma patient, even if no apparent VA injury occurs before and during the operation, the surgeon must take caution not to risk cerebral infarction because of the delayed VA dissection.

Key Words: Cervical trauma $\cdot$ Cervical fusion $\cdot$ Cerebral infarction $\cdot$ Vertebral artery dissection $\cdot$ Embolism

\section{INTRODUCTION}

Various techniques of fixation have been described and used successfully in treatment of patients with atlantoaxial instability $^{4,6-8,10,16,18)}$. Although posterior wiring techniques have been used in stabilization of the atlantoaxial joint, these simple procedures have been associated with high fusion failure rates due to their limited stiffness in rotation and require rigid postoperative immobilization ${ }^{7,13,14)}$. For this reason, technically demanding rigid screw fixation techniques, such as C1-2 transarticular screw fixation and the $\mathrm{C} 1$ lateral mass screw combined with C2 pedicle screw fixation have been developed ${ }^{4,5,8,11,14)}$. Both techniques are biomechanically superior to wiring tech-

\footnotetext{
- Received: January 14, 2015 • Revised: May 26, 2015

- Accepted: May 27, 2015

Corresponding Author: Seung Hwan Yoon, MD, PhD

Department of Neurosurgery, Inha University School of Medicine,

27 Inhang-ro, Jung-gu, Incheon 400-711, Korea

Tel: +82-32-890-2370, Fax: +82-32-890-2374

E-mail: nsyoon@gmail.com

"The authors declare that they have no proprietary, commercial, or financial interests that could be construed to have inappropriately influenced this study.

"This study has not been presented in part elsewhere.

$\otimes$ This is an Open Access article distributed under the terms of the Creative Commons Attribution Non-Commercial License (http://creativecommons.org/ licenses/by-nc/3.0/) which permits unrestricted non-commercial use, distribution, and reproduction in any medium, provided the original work is properly cited.
}

niques; however, they may carry a risk of iatrogenic injury to the vertebral artery $(\mathrm{VA})^{10,16,21)}$. The incidence of VA injury during posterior screw fixation of the C1-2 complex will probably remain unknown and under-reported ${ }^{11,13)}$. Vascular injury presented immediately after the penetration, but delayed onset of vascular symptom after cervical fusion is extremely rare ${ }^{19}$. We present here an extremely rare case of delayed onset of vascular symptom caused by an embolism and vessel dissection after cervical fusion without definite the screw breach in cervical traumatic atlantoaxial instability patient.

\section{CASE REPORT}

A 56-year-old woman visited our hospital complained of neck pain after traffic accident. There was no apparently definite abnormal result in neurologic examination with motor grade 5 in all extremities. The C-spine radiograms, computed tomography $(\mathrm{CT})$ and magnetic resonance (MR) images revealed cervical type II odontoid process fracture with traumatic spondylolisthesis type I (Fig. 1A). Because the patient complained the neck pain with excessive movement at the junction between $\mathrm{C} 1$ and $\mathrm{C} 2$, the posterior cervical fusion with pedicle screws $(\mathrm{C} 1$ and $\mathrm{C} 2)$ and lateral mass screws (C3) were performed after intraoperative odontoid process reduction under the guide of fluoroscopy (Fig. 1B). All pedicle screws were inserted with a free-hand technique. After creating a pilot hole and confir- 
ming no arterial bleeding or cerebrospinal fluid leakage, an appropriate pedicle screws were inserted. After the surgery, the patient was alert and neurologic findings did not show any apparent change. All screws were appropriately inserted without breach, injury of vertebral arteries, and no bleeding sign observed in postoperative CT (Fig. 1C, D, E and F).

On the sixth postoperative day, the patient had a seizure event with right side weakness. The vital signs were unstable with increased blood pressure (Fig. 2A). The checked brain CT revealed no definite abnormalities in intracranial lesions,
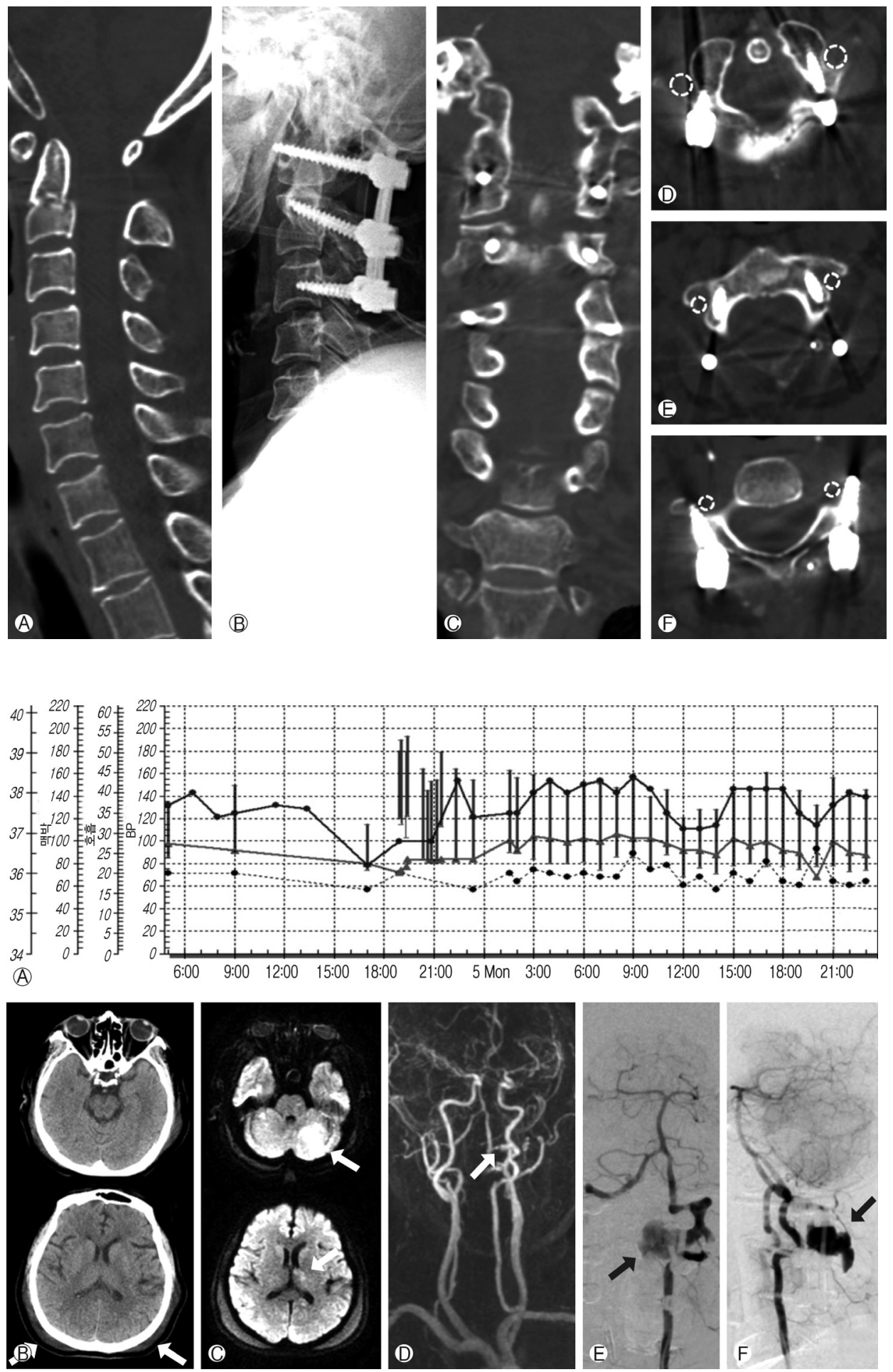

Fig. 2. The postoperative images. (A) The change of vital sign before and after seizure event. (B) computed tomography demonstrated no definite abnormalities except the hematoma and soft tissue swelling in posterior scalp (white arrows). (C) magnetic resonance images showed multifocal acute infarction (white arrow). (D) Stenosis in left vertebral and basilar artery was shown in magnetic resonance angiogram. ( $E$ and F) left vertebral artery (V3 segment) rupture was confirmed in anterior-posterior and lateral views of the cerebral angiography. 
but MR imaging showed multi-focal acute infarction in bilateral occipital lobe, left thalamus, left corpus callosum splenium and bilateral cerebellar hemispheres (Fig. 2B and C). MR angiograms showed stenosis in left vertebral artery and basilar artery (white arrow in Fig. 2D), and an angiography confirmed ischemic symptom by thromboembolism due to left VA (V3 segment) dissection (black arrows in Fig. 2E and F). The injury of vertebral artery (VA) by cervical screws was not observed in three dimensional digital subtraction angiographys (Fig. 3A, $\mathrm{B}, \mathrm{C}$ and $\mathrm{D})$. After the parent artery occlusion, the left VA dissection vanished (Fig. 3E and F). Six weeks after the parent artery occlusion, no evidence of acute infarct was observed in follow-up MR images. The patient had no neurological deficit with mild decreased comprehension.

\section{DISCUSSION}

There are some reports concerning the risk of cerebral infarction subsequent to VA injury or embolism caused by cervical fusion $^{14,16,19,22)}$. Complete occlusion or penetration of the VA at the injured site is thought to be responsible for the infarction $^{18)}$. Posterior fusion of the cervical spine is usually performed using a pedicle screw, lateral mass screw, and a spinous process plate; however, they may carry a risk of direct or indirect iatrogenic injury to the $\mathrm{VA}^{10,16,19,21)}$. Vascular injury

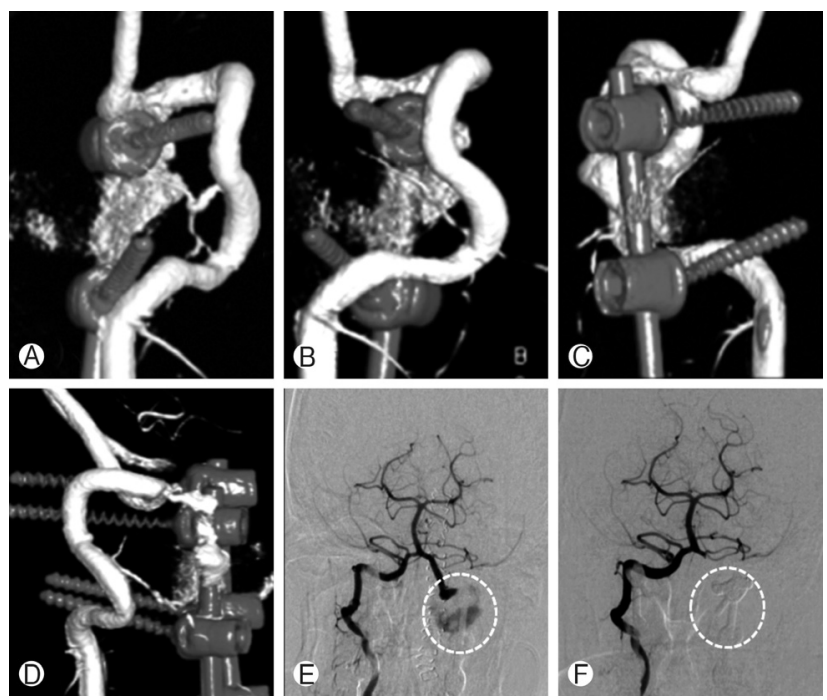

Fig. 3. The serial three dimensional digital subtraction angiographys and angiographys. (A, B, C and D) the injury of vertebral artery (VA) by cenvical screws were not observed in three dimensional digital subtraction angiographys. (E) before the parent artery occlusion, left VA dissection was observed by right VA selective angiography (white dot circle). (F) after the parent artery occlusion, left VA dissection was disappeared (white dot circle). presented immediately after the penetration, but delayed onset of vascular symptom after cervical fusion is extremely rare ${ }^{19)}$. To our knowledge, this is the first report of a delayed onset of vertebral artery dissection after posterior cervical fusion in cervical traumatic event.

Iatrogenic vertebral artery injury (VAI) is an uncommon complication resulting from various diagnostic and therapeutic procedures ${ }^{13)}$. Most cases of VA laceration in posterior cervical spine surgery have occurred during the C1-2 transarticular screw fixation procedure ${ }^{13)}$. Insertion of transarticular screws into the C1-2 facet joint could injure the VA, because of the proximity of the VA in the bony groove and the blind passage of the screws through the structures ${ }^{14,20,24)}$. A radiological analysis showed that placement of a C1-2 transarticular screw was unsafe in about $20 \%$ of the patients, secondary to an aberrant course of the VA or thin C2 pars/pedicle ${ }^{8)}$. Five (8\%) VA lacerations out of 61 patients with atlantoaxial instability who had undergone this procedure were also reported by Madawi et al. ${ }^{14)}$. In a large retrospective survey, VA injury had occurred in $4.1 \%$ of the 1,318 patients cumulatively evaluated ${ }^{24)}$. The large majority of patients remained asymptomatic after the incidence ${ }^{13)}$. But, the delayed onset of vascular symptom after cervical fusion due to pseudoaneurysm or arteriovenous fistula formation could happen as we presented ${ }^{16}$.

In fact, traumatic injury of the vertebral artery, although rare, can result in laceration, occlusion, dissection, pseudo-

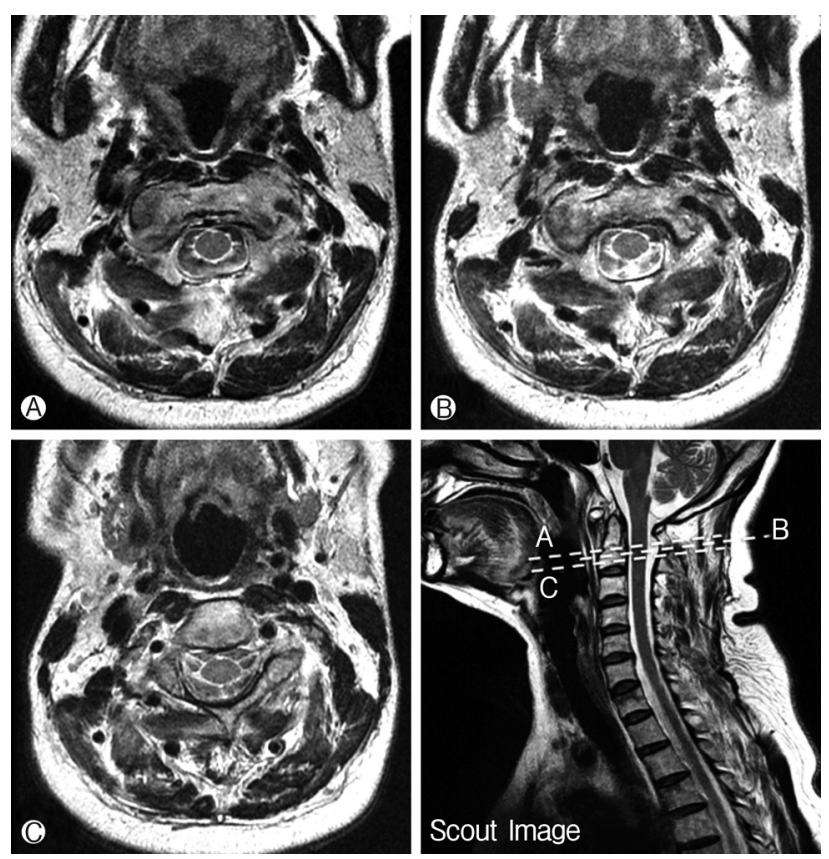

Fig. 4. The preoperative MR image around the dissected left VA. (A, B, C and Scout Image) indicated no definite vascular injury at the lesions. 
aneurysm formation or more rarely arteriovenous fistula formation $^{2,12,15)}$. Hairul et al. reported the majority of traumatic injuries of the vertebral artery had a delay in presentation of more than one day $(61 \%)^{1)}$. This presented case also visited the hospital after traffic accident and had no blunt penetration of screws during the operation, so delayed onset of vascular symptom could be happen by traumatic injury of the vertebral artery. But, in preoperative MR images (Fig. 4), the dissected left V3 segment was intact. Unfortunately, the authors did not checked preoperative angiography which could be conclusive evidence; however, no hematoma at the operation site in the postoperative CT images is also evidence of not traumatic cause of delayed VA dissection. But, another possible hypothesis is present, such as the impending artery rupture followed by the intimal injury after traumatic cervical event. So, traumatic injury of the vertebral artery by preoperative traffic accident was not a conclusive cause, but a subjective cause. Nevertheless its ambiguous cause of delayed VA dissection, this case informed the spine surgeon that the possible unusual hemorrhage event after cervical fusion in traumatic cervical patient.

Unilateral VA injury rarely leads to a lethal complication because the contralateral VA feeds cerebral circulation. Neo et al. ${ }^{17)}$ also reported that 15 patients with VA injury had no neurologic sequelae except for one patient who complained of vertigo. Taneichi et al. ${ }^{23)}$ reported that VA occlusions were rarely symptomatic, based on a prospective observation of 11 VA occlusions induced traumatically. Recently, endovascular management, such as coil embolization, stent-assist coil embolization, and the use of stent grafts or covered stents, has been introduced ${ }^{1,3,5,9)}$. It can be a good alternative in the treatment of VA injury as this presented case ${ }^{5)}$. Fortunately, this presented case illustrated a postoperative seizure with hemiparesis in 6 days after the operation, but improved to no neurological deficit with mildly decreased comprehension.

\section{CONCLUSION}

When a cervical operation performed in the cervical trauma patient, even if no apparent VA injury occurs before and during the operation, the surgeon must take caution not to risk cerebral infarction because of the delayed VA dissection. Endovascular management could be a good treatment of delayed VA dissection if it happened.

\section{REFERENCES}

1. Ahmad HA, Gerraty RP, Davis SM, Cameron PA: Cervicocere- bral artery dissections. J Accid Emerg Med 16:422-424, 1999

2. Amirijamshidi A, Abbassioun K, Rahmat H: Traumatic aneurysms and arteriovenous fistulas of the extracranial vessels in war injuries. Surg Neurol 53:136-145, 2000

3. Burke JP, Gerszten PC, Welch WC: Iatrogenic vertebral artery injury during anterior cervical spine surgery. Spine J 5:508-514, 2005

4. Chen JF, Wu CT, Lee SC, Lee ST: Posterior atlantoaxial transpedicular screw and plate fixation. Technical note. J Neurosurg Spine 2:386-392, 2005

5. Choi JW, Lee JK, Moon KS, Kim YS, Kwak HJ, Joo SP, et al: Endovascular embolization of iatrogenic vertebral artery injury during anterior cervical spine surgery: report of two cases and review of the literature. Spine 31:E891-E894, 2006

6. Coyne TJ, Fehlings MG, Wallace MC, Bernstein M, Tator CH: C1-C2 posterior cervical fusion: long-term evaluation of results and efficacy. Neurosurgery 37:688-692, 1995

7. Ebraheim N, Rollins JR Jr, Xu R, Jackson WT: Anatomic consideration of C2 pedicle screw placement. Spine 21:691-695, 1996

8. Epstein NE: From the neurointerventional lab...intraoperative cervical vertebral artery injury treated by tamponade and endovascular coiling. Spine J 3:404-405, 2003

9. Garcia Alzamora M, Rosahl SK, Lehmberg J, Klisch J: Lifethreatening bleeding from a vertebral artery pseudoaneurysm after anterior cervical spine approach: endovascular repair by a triple stent-in-stent method. Case report. Neuroradiology 47: 282-286, 2005

10. Golfinos JG, Dickman CA, Zabramski JM, Sonntag VK, Spetzler RF: Repair of vertebral artery injury during anterior cervical decompression. Spine 19:2552-2556, 1994

11. Heary RF, Albert TJ, Ludwig SC, Vaccaro AR, Wolansky LJ, Leddy TP, et al: Surgical anatomy of the vertebral arteries. Spine 21:2074-2080, 1996

12. Hossain M, Brown J, McLean AN, Fraser MH: Delayed presentation of post-traumatic aneurysm of the posterior inferior cerebellar artery in a patient with spinal cord injury. Spinal Cord 40:307-309, 2002

13. Inamasu J, Guiot BH: Iatrogenic vertebral artery injury. Acta Neurol Scand 112:349-357, 2005

14. Madawi AA, Casey AT, Solanki GA, Gerald T, Veres R, Crockard HA: Radiological and anatomical evaluation of the atlantoaxial transarticular screw fixation technique. J Neurosurg 86:961-968, 1997

15. Mortimer A, Stubbs E, Cookson D, Dawson R, Fleet M: Delayed presentation of a vertebral arterio-venous fistula secondary to penetrating cervical trauma: endovascular management using coil embolisation - a case report. J Radiol Case Rep 3:9-15, 2009

16. Nam KH, Sung JK, Park J, Cho DC: End-to-End Anastomosis of an Unanticipated Vertebral Artery Injury during C2 Pedicle Screwing. J Korean Neurosurg Soc 48:363-366, 2010

17. Neo M, Fujibayashi S, Miyata M, Takemoto M, Nakamura T: Vertebral artery injury during cervical spine surgery: a survey of more than 5600 operations. Spine 33:779-785, 2008

18. Oh CH, Ji GY, Seo HS, Yoon SH, Hyun D, Park H-C: Repeated complication following atlantoaxial fusion: a case report. Korean J Spine 11:7-11, 2014. 
19. Onishi E, Sekimoto Y, Fukumitsu R, Yamagata S, Matsushita M: Cerebral infarction due to an embolism after cervical pedicle screw fixation. Spine 35:E63-E66, 2010

20. Paramore CG, Dickman CA, Sonntag VK: The anatomical suitability of the C1-2 complex for transarticular screw fixation. J Neurosurg 85:221-224, 1996

21. Prabhu VC, France JC, Voelker JL, Zoarski GH: Vertebral artery pseudoaneurysm complicating posterior C1-2 transarticular screw fixation: case report. Surg Neurol 55:29-33, 2001

22. Sakamoto T, Neo M, Nakamura T: Transpedicular screw placement evaluated by axial computed tomography of the cervical pedicle. Spine 29:2510-2514, 2004

23. Taneichi H, Suda K, Kajino T, Kaneda K: Traumatically induced vertebral artery occlusion associated with cervical spine injuries: prospective study using magnetic resonance angiography. Spine 30:1955-1962, 2005

24. Wright NM, Lauryssen C: Vertebral artery injury in C1-2 transarticular screw fixation: results of a survey of the AANS/CNS section on disorders of the spine and peripheral nerves. American Association of Neurological Surgeons/Congress of Neurological Surgeons. J Neurosurg 88:634-640, 1998 